\title{
Quantitation of lactoferrin in odontogenic cyst fluids
}

\author{
C W I DOUGLAS, G T CRAIG \\ From the Department of Oral Pathology, University of Sheffield, Sheffield
}

SUMMARY A competitive enzyme linked immunosorbent assay (ELISA) method was used to measure the concentration of lactoferrin in fluids from 36 odontogenic keratocysts, 15 dentigerous cysts, and 30 radicular/residual cysts. Keratocyst fluids contained significantly higher concentrations of lactoferrin than fluids from the other two types of cyst $(p<0.001)$; but the range of values obtained within each group was large. Although lactoferrin represents a larger proportion of the total protein in keratocyst fluids than in dentigerous or radicular cyst fluids, lactoferrin concentration is not an absolute diagnostic marker for keratocysts. Lactoferrin concentration correlated strongly with the numbers of neutrophils present in keratocyst fluids ( $p<0.001)$, less so for dentigerous cyst fluids ( $p$ $<0.05$ ), and not at all in the case of radicular cyst fluids.

It is suggested that neutrophils are the source of lactoferrin in the three categories of cyst studied but that the relatively impermeable nature of the keratocyst lining probably accounts for the particularly high concentrations of lactoferrin found in their fluids. Given that most keratocysts were asymptomatic, acute inflammation itself does not explain the reason for the high numbers of neutrophils in many of the fluids.

Odontogenic keratocysts tend to behave more aggressively and to recur more frequently following surgical removal than other types of odontogenic cyst.' It is important, therefore, to distinguish odontogenic keratocysts from other cysts preoperatively, and towards this end studies have been carried out on the fluids that can be aspirated from odontogenic cysts. Toller examined the total soluble protein concentrations in such fluids and showed that keratocyst fluids contained significantly lower concentrations of protein than non-keratinising odontogenic cysts ${ }^{2}$; along with the presence of keratinised squames in the fluid, these are the criteria widely used to support a preoperative diagnosis of odontogenic keratocyst. ${ }^{3}$

Protein estimation as a diagnostic criterion, however, can be problematic as some cysts become heavily inflamed or infected and fluids are often contaminated with blood during aspiration, all of which could raise the protein concentration in the fluid. More specific markers for diagnosis of odontogenic keratocysts have thus been sought and among those reported are "prealbumin", ${ }_{4}$ a keratin-like component, ${ }^{5}$ and an antigen, originally designated $\mathrm{X},{ }^{6}$ which on further analysis proved indistinguishable from lactoferrin. ${ }^{7}$ Douglas and Craig reported that lactoferrin seemed to be specific to odontogenic keratocysts when they used crossed immunoelectrophoresis as the screening method, ${ }^{7}$ but this work was based on a relatively small

Accepted for publication 21 September 1988 number of fluids. Examination of a larger group of fluids and using an enzyme linked immunosorbent assay (ELISA) as the screening method showed that lactoferrin was also detectable in several fluids derived from non-keratinising odontogenic cysts, although initial results suggested that keratocyst fluids contained higher concentrations of lactoferrin. ${ }^{8}$ This work has now been extended using a sensitive competitive ELISA technique and is reported here.

\section{Material and methods}

Eighty one cyst fluids that had been aspirated from cystic lesions histologically diagnosed as odontogenic keratocysts ( $\mathrm{n}=36$, from 31 cases), dentigerous cysts $(n=15)$, or radicular/residual cysts $(n=30)$ were studied. Duplicate smears of each fluid were routinely stained by the methods of Papanicolaou and Gram and the remainder of the fluids were centrifuged at $11600 \mathrm{~g}$ for five minutes in an MSE microcentaur centrifuge. The concentration of total soluble protein in the supernatant was then estimated by the method of Lowry. ${ }^{9}$ Fluids were stored at $-20^{\circ} \mathrm{C}$ until further use.

For the ELISA 96-well trays (Flow Laboratories Ltd, Irvine, Scotland) were coated with lactoferrin (Sigma; $500 \mathrm{ng} / \mathrm{ml}$ ) in $50 \mathrm{mM}$ carbonate buffer, pH9.6, overnight at $4^{\circ} \mathrm{C}$. Trays were washed in PBS containing $0.05 \%$ Tween 20 , and lactoferrin standards or cyst fluids were diluted (range $1 / 10-1 / 10000$ ) in 
dilute $(1 / 3000)$ rabbit anti-lactoferrin serum (Dako) and immediately added to the wells. The immobilised lactoferrin was, therefore, in competition with free lactoferrin in solution for the anti-lactoferrin immunoglobulin. Antibody binding to the immobilised phase was subsequently detected with peroxidaseconjugated swine anti-rabbit IgG (1/1000; Dako) and developed with o-phenylenediamine $(400 \mu \mathrm{g} / \mathrm{ml})$. All fluids were tested in duplicate and duplicate lactoferrin standards (range $15 \cdot 75-500 \mathrm{ng} / \mathrm{ml}$ ) were included in each tray.

Duplicate smears of each fluid were examined for the presence of neutrophils on a subjective $0-3+$ scale. Each fluid was scored without knowledge of the cyst type from which it was derived or the lactoferrin concentration of the fluid. The score given was an average for five, randomly chosen, high power fields.

All data were analysed by a non-parametric statistical test (Mann-Whitney) using the BBC computer "Microtab" statistics package.

\section{Results}

\section{PROTEIN AND LACTOFERRIN CONCENTRATION} Odontogenic keratocyst fluids contained significantly lower concentrations of protein (mean (SD) $5 \cdot 2(3.8)$, median $4.2 \mathrm{~g} / 100 \mathrm{ml} ; \mathrm{p}<0.001)$ than dentigerous (mean (SD) $9.7(3.8)$, median $7.9 \mathrm{~g} / 100 \mathrm{ml}$ ), or radicular/residual cyst fluids (mean (SD) 9.2 (3.4), median $8.6 \mathrm{~g} / 100 \mathrm{ml}$ ), there being no significant difference between the latter two groups. The range of values for keratocyst fluids, however, $(0 \cdot 06-15 \cdot 8 \mathrm{~g} / 100$ $\mathrm{ml})$ overlapped those obtained for dentigerous $(6 \cdot 1-$ $17 \cdot 3 \mathrm{~g} / 100 \mathrm{ml})$ and radicular/residual cyst fluids $(2 \cdot 8$ $18.0 \mathrm{~g} / 100 \mathrm{ml}$ ).

The competitive ELISA method used here produced data which were reproducible within a $10 \%$ error when assayed on separate occasions, and between duplicate samples when assayed on the same occasion. The sensitivity of the method permitted detection of as little as $30 \mathrm{ng} / \mathrm{ml}$ of lactoferrin in each diluted sample.

Table 1 shows that the mean lactoferrin concentration in keratocyst fluids was significantly higher ( $p<$ 0.01 ) than the concentrations in dentigerous or radicular cyst fluids. Notwithstanding this population

Table 1 Lactoferrin concentration $(\mu \mathrm{g} / \mathrm{ml})$ in odontogenic cyst fluids

\begin{tabular}{lccc}
\hline & $\begin{array}{l}\text { Odontogenic } \\
\text { keratocysts }\end{array}$ & $\begin{array}{l}\text { Dentigerous } \\
\text { cysts }\end{array}$ & $\begin{array}{l}\text { Radicular/ } \\
\text { residual cysts }\end{array}$ \\
\hline No & 36 & 15 & 30 \\
Range & $0.6-3432$ & $0.8-3258$ & $0.6-1413$ \\
Mean (SD) & $736(891)$ & $236(836)$ & $161(338)$ \\
Median & 214 & 21 & 29 \\
& $\longleftarrow$ & $\mathrm{Ns}<0.01 \stackrel{\mathrm{p}<0.01}{\longrightarrow}$ \\
\hline
\end{tabular}

Table 2 Lactoferrin concentration ( $\mu \mathrm{g} / \mathrm{mg}$ protein) in odontogenic cyst fluids

\begin{tabular}{llll}
\hline & $\begin{array}{l}\text { Odontogenic } \\
\text { keratocysts }\end{array}$ & $\begin{array}{l}\text { Dentigerous } \\
\text { cysts }\end{array}$ & $\begin{array}{l}\text { Radicular/ } \\
\text { residual cysts }\end{array}$ \\
\hline No* & 35 & 14 & 29 \\
Range & $0.007-87$ & $0.002-34$ & $0.006-16$ \\
Mean (SD) & $20(28)$ & $2.5(8.5)$ & $1.9(3.6)$ \\
Median & 8.7 & 0.4 & 0.27 \\
& $\stackrel{\mathrm{p}}{2}<0.001 \stackrel{\mathrm{NS}}{\longrightarrow} \mathrm{p}<0.001-$ \\
\hline
\end{tabular}

*No protein estimation available for one odontogenic keratocyst fluid, one dentigerous cyst fluid, and one radicular fluid.

difference, the range of values for the three groups of fluids overlapped considerably, as shown by the large standard deviation in each case. When the lactoferrin concentration in each cyst fluid was compared with the protein concentration for the same fluid, no correlation between them was found irrespective of cyst type. When the lactoferrin concentration was expressed as a function of total protein present, however, a higher proportion of the protein in keratocyst fluids than in fluids from the other cyst types was lactoferrin (table 2).

\section{CORRELATION OF LACTOFERRIN WITH}

\section{INFLAMMATION}

Permanent smear preparations of each cyst fluid had been made on receipt of each specimen; but because the material used for this study had been collected over several years no standardised method of smear preparation had been used for all samples. Thus when smears were examined for numbers and types of inflammatory cells, estimations could only be made subjectively on a $0-3+$ scale, and results should be interpreted with caution. Notwithstanding this limitation, a highly significant correlation between lactoferrin concentration and numbers of neutrophils present in keratocyst fluids was found $(r=0.55 ; p<$ 0.001 ). A less significant correlation was found for dentigerous cyst fluids $(r=0.56 ; p<0.05)$, but no correlation was found for radicular/residual cyst fluids $(\mathrm{r}=0.31 ; \mathrm{p}<0 \cdot 1)$.

Most lesions from which the cyst fluids were derived had been asymptomatic clinically, suggesting lack of acute inflammation. Table 3 shows the mean neutro-

Table 3 Clinical state v polymorphonuclear leucocytes

\begin{tabular}{llll}
\hline & $\begin{array}{l}\text { Odontogenic } \\
\text { keratocysts }\end{array}$ & $\begin{array}{l}\text { Dentigerous } \\
\text { cysts }\end{array}$ & $\begin{array}{l}\text { Radicular/ } \\
\text { residual cysts }\end{array}$ \\
\hline Painless & $29(1 \cdot 8)$ & $11(1 \cdot 1)$ & $21(1 \cdot 4)$ \\
Painful & $7(2 \cdot 3)$ & $4(2 \cdot 0)$ & $9(2 \cdot 0)$ \\
\hline
\end{tabular}

Figures in parentheses represent mean neutrophil scores for fluids from each category of cyst. 
phil score for each category of cyst divided on the basis of clinical state. Although in the main, lesions presenting with pain contained large numbers of neutrophils (a score of 2-3+), no correlation between the score for neutrophils in each cyst fluid and its clinical state was found. Many asymptomatic keratocysts also contained numerous neutrophils.

\section{Discussion}

The competitive ELISA method used here was a sensitive and reproducible means for assaying lactoferrin concentration in odontogenic cyst fluids. All fluids studied were found to contain lactoferrin and therefore, despite earlier indications, lactoferrin is not an absolute marker for odontogenic keratocysts. That said, lactoferrin concentration as a function of the total protein present seems to be no less valid a diagnostic feature than total soluble protein concentration alone.

Keratocyst fluids usually contain a total soluble protein concentration of $4.0 \mathrm{~g} / 100 \mathrm{ml}$ or less, ${ }^{29}$ while radicular/residual and dentigerous cyst fluids usually contain more than $4.0 \mathrm{~g} / 100 \mathrm{ml}$. Of the keratocyst fluids studied, $19(54 \%)$ had a protein concentration greater than $4.0 \mathrm{~g} / 100 \mathrm{ml}$ and one $(3 \%)$ of radicular/ residual cyst fluids contained less than $4.0 \mathrm{~g} / 100 \mathrm{ml}$. If the protein concentration "cut-off" were raised to $5 \cdot 0$ $\mathrm{g} / 100 \mathrm{ml}$ the number of false negative diagnoses of keratocysts would be reduced to $34 \%$ while the number of radicular/residual cyst false negative diagnoses would have risen to $10 \%$. All dentigerous cyst fluids contained more than $5.0 \mathrm{~g} / 100 \mathrm{ml}$ protein. On the other hand, if lactoferrin concentration were used as a diagnostic criterion, say at a minimum concentration of $2.0 \mu \mathrm{g} / \mathrm{mg}$ protein for keratocyst fluids, only $25 \%$ of keratocysts would be diagnosed incorrectly while $6 \%$ of dentigerous cysts and $20 \%$ of radicular cysts would be misdiagnosed. In terms of its diagnostic value for keratocysts, then, lactoferrin concentration is as valid as soluble protein concentration; but in practice protein concentration is rarely relied on alone for diagnosis as fluids are also usually examined for the presence of keratinised squames. $^{3}$

Immunohistochemical staining of the lining epithelia of odontogenic keratocysts has failed to detect lactoferrin, and although lactoferrin is found in certain other epithelia, these are secretory in nature. ${ }^{10}$ The other known major source of lactoferrin is the azurophilic granules of neutrophils." This seems to be the most likely origin for lactoferrin in keratocyst fluids because of the strong correlation between neutrophil density and lactoferrin concentration in these fluids. Given the developmental, and by implication noninflammatory, pathogenesis of keratocysts, however, it might be expected that fluids from the inflammatory radicular/residual cysts would yield the highest concentrations of lactoferrin. Certainly, evaluation of smear preparations confirmed that fluids from radicular cysts contained the most neutrophils, with dentigerous cyst fluids containing the least and keratocysts with intermediate amounts. A possible mechanism to account for this finding implicates the nature of the keratocyst lining, which Toller considered to be relatively impermeable to proteins with molecular weights greater than albumin (68 000 daltons). ${ }^{1213}$ The molecular weight of lactoferrin is in the range 77-85 000 Daltons ${ }^{14}$ is and so its ability to diffuse through the keratocyst lining might be expected to be impeded. Thus if neutrophils degranulate within the keratocyst lumen lactoferrin may become concentrated over time due to its inability to escape. This would be in contrast to the situation expected in radicular/residual cysts where the lining epithelium is not normally keratinised, and intraepithelial channels have been recognised through which neutrophil traffic passes. ${ }^{16}$ Lactoferrin might therefore readily diffuse into the surrounding tissue, lowering its concentration in radicular/residual cyst fluids. It must be borne in mind that such an explanation is purely speculative given the information presently available.

Another question which arises from the data presented is this: why do most keratocyst fluids contain clinically important numbers of neutrophils despite the cysts' non-inflammatory pathogenesis? This question also needs to be considered alongside the finding that 29 of 36 keratocyst fluids came from lesions that were asymptomatic clinically and in which the neutrophil score was greater than for many asymptomatic cases of the other cyst types. In a recent histological study of 112 keratocysts Rodu et al observed chronic inflammation in $76 \%$ of cases but virtually no evidence of acute inflammation or abscess formation was found.$^{16}$ Other authors have also noted the presence of chronic inflammation in the linings of most keratocysts, ${ }^{17-19}$ and Matthews and Browne showed immunohistochemically that the cell infiltrate mainly consisted of macrophage-type cells and a mixture of $T$ and $B$ lymphocytes. ${ }^{20}$ No difference between the various odontogenic cyst types could be found in respect of this inflammatory cell infiltrate. Accordingly, it seems clear that our finding of a substantial neutrophil population in keratocyst fluids cannot be explained on the basis of acute inflammation in the cyst lining and wall.

In an attempt to explain the presence of neutrophils in keratocyst fluids we again implicate the nature of the cyst lining. It is known that when human stratum corneum is implanted into animal connective tissue a vigorous acute inflammatory response ensues ${ }^{21}$; furthermore, when epidermoid or dermoid cysts rupture exposing their horny contents to the dermis, 
neutrophils are attracted to the site. ${ }^{22}$ This response is now thought to be mediated by interleukin-1 (IL-1), as this substance has been found in saline extracts of normal stratum corneum ${ }^{23}$ and IL-1 (formerly known as epidermal-derived thymocyte activating factor) is both chemotactic to neutrophils and an activator of $T$ cells. ${ }^{24}{ }^{25}$ Thus it is tempting to speculate that the neutrophil accumulation in keratocyst fluids is in response to the keratinised cell lining and possibly its IL-1 product. IL-1 is also known to stimulate neutrophil metabolism which leads to the release of granule components. $^{23}$

Notwithstanding these interesting possibilities for a role for IL-1 in lactoferrin accummulation in keratocyst fluids, sight must not be lost of the finding that a proportion of keratocyst fluids in our study contained only very low lactoferrin concentration and few neutrophils. IL-1 would be an expected product of all keratocyst linings and so all fluids from these lesions should contain neutrophils and lactoferrin. The early phase of keratinocyte proliferation, however, has been shown to produce much more IL-1 than the later keratinising phase ${ }^{26}$ and so the stage or age of the lesion may influence the number of neutrophils attracted. Inevitably, the pathogenesis of odontogenic cysts involves numerous factors and further investigation is required.

\section{References}

1 Pindborg JJ, Hansen J. Studies on odontogenic cyst epithelium. 2. Clinical and roentgenologic aspects of odontogenic keratocysts. Acta Pathol Microbiol Scand (A) 1963;58:283-94.

2 Toller PA. Origin and growth of cysts of the jaws. Ann R Coll Surg Engl 1967;40:306-36.

3 Kramer IRH, Toller PA. The use of exfoliative cytology and protein estimations in preoperative diagnosis of odontogenic keratocysts. Int J Oral Surg 1973;2:143-51.

4 Davies JD, Southgate J, Whicher JT, Matthews RW. Novel antigenic marker of squamous epithelium: keratocyst anodal protein. J Pathol 1984;142:29-30.

5 Kuusela P, Ylipaavalniemi P, Thesleff I. The relationship between the keratocyst antigen (KCA) and keratin. J Oral Pathol 1986; 15:287-91.

6 Douglas CWI, Craig GT. Recognition of a protein apparently specific to odontogenic keratocyst fluids. J Clin Pathol 1986; 39:1108-15.

7 Douglas CWI, Craig GT. Evidence for the presence of lactoferrin in odontogenic keratocyst fluids. J Clin Pathol 1987;40:914-21.

8 Douglas CWI. The identification of lactoferrin in odontogenic keratocyst fluids. J Dent Res 1987;66:835.

9 Smith G, Smith AJ, Browne RM. Protein differences in odontogenic cyst fluids. IRCS Med Sci 1983;11:117.

10 Masson PL, Heremans JH, Dive $\mathbf{C H}$. An iron-binding protein common to many external secretions. Clin Chim Acta 1966; 14:735-9.

11 Hurlen B, Olsen I, Lingaas E, Midtvedt T. Neutrophil phagocytosis of Treponema denticola as indicated by extracellular release of lactoferrin. Acta Pathol Microbiol Immunol Scand B 1984;92:171-3.

12 Toller PA. Permeability of cyst walls in vivo: Investigations with radioactive tracers. Proc Roy Soc Med 1966;59:724-9.

13 Toller PA. The osmolarity of fluids from cysts of the jaws. Br Dent J 1970;129:275-8.

14 Oram JD, Reiter B. Inhibition of bacteria by lactoferrin and other iron-chelating agents. Biochim Biophys Acta 1968;170:351-65.

15 Querinjean P, Masson PL, Heremans JF. Molecular weight, single chain structure and amino acid composition of human lactoferrin. Eur J Biochem 1971;20:420-5.

16 Cohen MA. Pathways of inflammatory cellular exudate through radicular cyst epithelium. A light and scanning electron microscope study. J Oral Pathol 1979;8:369-78.

17 Rodu B, Tate AL, Martinez Jr MG. The implications of inflammation in odontogenic keratocysts. J Oral Pathol 1987;16:518-21.

18 Brannon RB. The odontogenic keratocyst. A clinicopathologic study of 312 cases. Part II. Histologic features. Oral Surg 1977; 43:233-55.

19 Wright JM. The odontogenic keratocyst: orthokeratinised variant. Oral Surg 1981;51:609-18.

20 Woolgar JM, Rippin JW, Browne RM. A comparative study of the clinical and histologic features of recurrent and non-recurrent odontogenic keratocysts. J Oral Pathol 1987;16:124-8.

21 Matthews JB, Browne RM. An immunocytochemical study of the inflammatory cell infiltrate and epithelial expression of HLADR in odontogenic cysts. J Oral Pathol 1987;16:112-7.

22 Dalziel K, Dykes PJ, Marks R. Inflammation due to intracutaneous implantation of stratum corneum. Br J Exp Pathol 1984;65:107-15.

23 Gahring LC, Buckley A, Daynes RA. Presence of epidermalderived thymocyte activating factor/interleukin 1 in normal human stratum corneum. $J$ Clin Invest 1985;76:1585-91.

24 Luger TA, Charon JA, Colot M, Micksche M, Oppenheim JJ. Chemotactic properties of partially purified human epidermal cell derived thymocyte-activating factor (ETAF) for polymorphonuclear and mononuclear cells. J Immunol 1983;131:816-20.

25 Sauder DN, Movick M, Hunningshake G. Human epidermal cell derived thymocyte-activating factor is a potent T-cell chemoattractant. J Invest Dermatol 1984;82:399.

26 Luger TA, Stadler BM, Katz SI, Oppenheim JJ. Epidermal cell (keratinocyte) derived thymocyte-activating factor (ETAF). $J$ Immunol 1981;127:1493-8.

Requests for reprints to: Dr C W I Douglas, University of Sheffield, Department of Oral Pathology, 31 Claremont Crescent, Sheffield S10 2TA, England. 